of a shilling, which extended through the coats of the bladder. There was no other sign of injury to the bladder. The urethra was not injured. The pelvis was very exten. sively fractured; on the right side each of the rami of the pubis was fractured about an inch from the symphysis, and through another fracture the head of the right femur was exposed. The left side of the pubic arch was fractured in three places, and a large fragment of its middle part was lying detached from the rest.

$$
\text { ( } T \text { o be concluded.) }
$$

\section{CYSTOTOMY IN SUBACUTE CYSTITIS.} By GEORGE ELDER, M.D.,

SURGEON TO THE HOSPITAL FOR WOMEN, NOTTINGHAM.

THE chronicity and intractability to the usual methods of treatment of catarrhal cystitis, especially in the aged, is my excuse for placing on record the undermentioned case, illustrating, as it does, the strikingly successful result obtained by cystotomy and subsequent drainage when all other means, local and general, had been long and fairly tried. The patient was a woman aged seventy-two years, with a rheumatic history, who was admitted under me at the Women's Hospital on Dec. 12th, 1882. For months previously she had been under medical attendance at home, suffering similarly to what she complained of on admission. There was incontinence of urine, accompanied with frequent desire to micturate, vesical tenesmus, dysuria, and constant burning hypogastric and vulvar pain. 'The calls to urinate were so frequent that it was impossible to obtain a night's rest. The vulva and contiguous skin were excoriated, and the seat of intense pruritus. There was considerable constitutional disturbance and declension in health. The urine was rather scanty; specific gravity 1018 ; offensively ammoniacal, and depositing abundantly pusłand ropy mucus. Microscopic examination in addition showed the presence of pavement and cylindrical epithelium, a few fibrinous casts and phosphates.

Between December 12th and February 23rd all the ordinary medication, local and general, was tried, embracing rest in bed, hip baths, plain and medicated vesical injections, emptying the bladder at short intervals, alkalies, acids with and without sedatives, with the effect of relieving her distressed condition, but productive of no permanent improvement in the condition of the urine. Her general health also did not mend; so under ether a vesico-vaginal fistula was produced on the latter-mentioned date, and a winged catheter attached to a long piece of rubber tubing inserted. The rest given to the intlamed viscus by drainage combined with injections, first of a solution of hyposulphite of soda, and afterwards dilute nitric acid combined with quinine internally, and acidulated drink $a d l i b$., soon effected a change for the better in her local condition. Speedy relief was given to the tenesmus, weight and local pains, and on April 28th it was noted that for three days the drainage-tube had not been in place, and the urine which could be retained from two to three hours was passed per urethram without discomfort. No urine came through the fistulous opening, and it was clear, faintly acid, and depositing only a slight cloud of mucus. On May 9th she left the hospital entirely cured of her bladder troubles, passing painlessly perfectly healthy urine. The fistulous opening required no application beyond nitrate of silver. On May 31st the patient came to see me, and reported herself as able to retain her urine between three and four hours. The urine is normal and the fistulous opening closed.

Nottingham.

The Nightingale Fund.-From the report for 1882 of this fund it appears that thirty-six probationer nurses were admitted to the school at St. Thomas's Hospital during the year and that thirty-two completed their year's training and received appointments. From the opening of the school in June. 1860, to the end of 1882 , a total of 686 candidates have been admitted, and 414 have been entered on the Register as certified nurses. The receipts during the year amounted to $£ 3390$ and the expenditure to $£ 1840$, leaving a balance of $£ 1550$. The annual gratuity of $£ 2$ allowed by the regulations for the term of three years to certified nurses who have completed satisfactorily a year's service in some approved hospital was awarded to fifty-seven nurses.

\section{ACUTE RHEUMATISM AS A PREMONITORY} SYMPTOM OF PHTHISIS.

\author{
BY JOHN ALFRED AUSTIN, M.D.
}

RHEUMATIC FEVER has never been, as far as I am aware, put forward by any writer or observer as a premonitory symptom of phthisis. I have not even seen it mentioned, that an attack simulating acute rheumatism, and preceding the pulmonary symptoms, is occasionally observed as a phenomenon in the clinical history of that disease. Within the last few years, however, I have had under my observa. tion no less than four cases of phthisis, in which the more decided pulmonary symptoms had been immediately preceded by the ordinary symptoms of acute rheumatism, where the lung disease seemed to have lain dormant and to have been suddenly ushered into life and activity on the outbreak of the rheumatic attack. The swelling and redness of the joints and other symptoms, though not very severe, were sufficiently characteristic of rheumatic fever to prevent any error in diagnosis, and duly abated under the alkaline and opium or salicine treatment. The occurrence of four such cases in my practice within the space of three years entitles me, it must be allowed, to a reasonable suspicion that there might be something more than chance in bringing about such a coincidence, that a rational explanation might yet be found for the curious fact, and that this might be classed among the many strange and capricious symptoms of phthisis, which often foreshadow with terrible certainty the advent of the dread disease. To understand and rightly interpret these omens is worth something to the practitioner, who has not only to anticipate the contingencies of each individual case that comes under his care, but has a reputation to maintain among his patients for far-sightedness and correct prognosis.

I will now briefly sketch the history of the cases referred to.

CASE 1.-L. M- a young girl, seventeen years of age, complained from time to time of severe rheumatic pains in the joints of the lower limbs. This is the only case in which redness and swelling of the affected joints were absent. After the pain bad lasted a day or two, a copious eruption usually broke out all over the limbs, from the knees downwards, which had the effect of immediately relieving the pain. The eruption was a species of purpura--peliosis rheumatica. The attacks recurred from time to time, followed by more or less of the eruption, the relief from these attacks being always in proportion to the copiousness of the eruption. More than a year elapsed, and the girl was not thriving. The rheumatism to which she had been subject being hardly sufficient to account for the fact, I made repeated and careful examination of the chest, and eventually detected a small area of partially solidified lung in the left side. I expressed an opinion that one of the lungs was affected, and recommended the parents to give her cod-liver oil and iodide of iron. The idea of the lung being affected was such an unwelcome surprise to these people that they consulted another practitioner at once, who attributed matters to delayed menstruation, and predicted a speedy return to health. Within eighteen months this poor girl died of phthisis.

CASE 2.-M. S—, a tall strong-looking young woman, twenty years of age, general servant, consulted me for pain in ber back. Suspecting it might have a uterine origin $I$ made special investigation, but elicited nothing to confirm my suspicions, and came to the conclusion, somewhat reluc tantly, that it was due to lumbago. A few days afterwards, however, this patient was prostrated on her bed with all the ordinary signs and symptoms of rheumatic fever-knees swollen, red, and painful, ankles and wrists also affected. and temperature increased. Under the administration of salicine these symptoms gradually subsided, and I discon. tinued my attendance. I had not thought of examining the chest. I heard nothing more of this patient for nearly two years, when I was informed that she was brought home from the South in the last stage of consumption. She died a few months after reaching home.

CASE 3.-C. M. L- a shepherd's daughter, aged twentyone, was said to be ill with rheumatic fever. On arriving at the bedside of this patient I was on the alert to discover something more than rheumatism, and naturally directed a 